\title{
Gold Compounds for Rheumatoid Arthritis *
}

\author{
Blaine M. Sutton \\ Department of Medicinal Chemistry, Smith Kline and French Laboratories, Philadelphia, Pennsylvania, U.S.A.

\begin{abstract}
Auranofin [2,3,4,6-tetra-0-acetyl-1-tbio-B-D-ghucopyranosato-S)-(trietbylphosphine)gold], a new gold compound for treating rheumatoid arthritis $(R A)$, is unique in that it produces its therapeutic benefit when administered by the oral route. Currently used gold preparations (sodium aurothiomalate, aurotbioghucose) must be given by injection to be effective. Auranofin has been used in the treatment of RA patients in clinical trials, and is comparable in efficacy to presently used injectable agents. Side effects with auranofin are mild in nature and result in fewer withdrawals from therapy than do injectable gold preparations.
\end{abstract}

The use of gold compounds in treatment of rheumatoid arthritis (RA) is well established, (1,2). Auranofin, $[2,3,4,6$-tetra-0-acetyl-1thio- $\beta-D$-glucopyranosato- $S$ )(triethylphosphine)gold], is a new antiarthritic gold coordination complex with unique properties $(3,4)$. It is therapeutically effective when given by the oral route. Other gold compounds now used to treat RA must be given by injection.

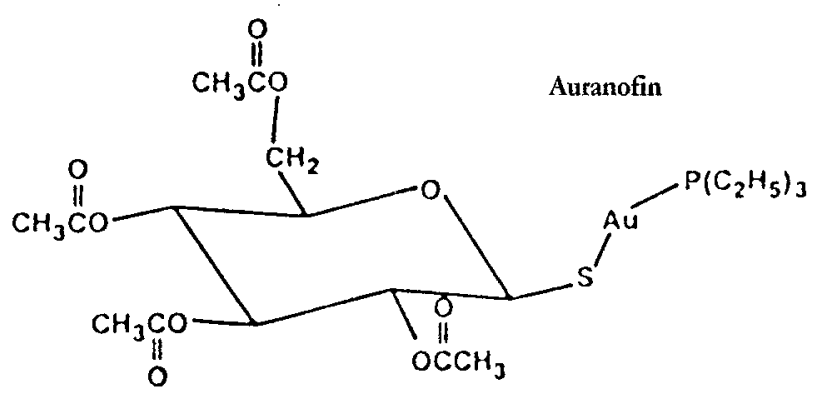

\section{History}

Gold is a metal with an aura of mysticism that has led to a long history of medical applications and its use for these purposes through the ages has been well reviewed recently in this journal by G. Higby (Gold Bull., 1982, 15, (4), 130-140). As early as 2500 BC Chinese and Arabic physicians used gold preparations in their practice of medicine (5). Medieval physicians(e.g. Paracelsus) used mixtures and ointments of colloidal gold for various ulcerative skin conditions including theumatism (6). However, it was not until Koch, 1890 (7) that biological properties of gold compounds were supported by experimental laboratory data.

Robert Koch at that time reported in vitro antitubercular activity of gold cyanide at a dilution of 1:2 millions - a concentration much too low to invoke cyanide ion as the active agent. Koch was unable to demonstrate that gold salts exhibited antitubercular activity in experimental animals and did not pursue their use further. Later potassium gold chloride was reported of benefit in lupus vulgarus

*This article is a slightly revised version of a paper first given at an IPMI conference, June 13th, 1985 and is reprinted by kind permission of the IPMI. and syphilis, and sodium aurothiomalate in tuberculosis. The gold decade (1925-1935) saw extensive use of intravenously administered gold salts for treatment of tuberculosis (8). Antitubercular benefits of the gold treatment proved to be non-existent and associated severe toxicity was frequent. This resulted in a search for safer and more effective agents. However, observations of the relief from joint pain in a group of non-tubercular patients treated with sodium aurothiomalate led Jacques Forestier to initiate a study of gold compounds for treatment of theumatoid arthritis (RA). In 1935 Forestier reported (9) the results of a six year study supporting the beneficial effects of gold salts in slowing the evolution of RA. He continued to be a champion of chrysotherapy until his death in 1979. Later double blind clinical studies by the Empire Rheumatism Council (1961) confirmed Forestier's observations, documenting the benefit of sodium aurothiomalate in RA. Radiological evidence of the benefit of gold salts in $\mathrm{RA}$ was reported by John Sigler (10). He observed that gold salts slow down and often eliminate the progressive chronic joint changes associated with $\mathrm{RA}$.

\section{Rheumatoid Arthritis}

What is RA and what differentiates it from related diseases? The American Rheumatism Association classifies numerous disease entities under the broad heading of rheumatic diseases (11). Most prevalent of these is osteoarthritis (degenerative joint disease), often associated with ageing. Following that in frequency is theumatoid arthritis, a progressive crippling disease of connective tissue that is not age-selective. In the U.S.A. there are approximately 6 million RA patients. Women account for about 75 per cent of this population. The disease adopts a chronic course in about 75 percent of RA patients and becomes rapidly progressive in greater than 15 per cent of those involved. The most common onset is at $20-45$ years of age:

Diagnosis of RA is non-specific and depends upon a combination of observations: evidence of joint involvement (visual or X-ray), high erythrocyte sedimentation rate, turbid synovial fluid with reduced viscosity, abnormal immunoglobulin (rheumatoid factor). The disease is characterised by progressive joint involvement leading to loss of function as a result of joint fusion with newly formed bone.

The etiology and pathogenesis of RA remains unknown. 
However, events associated with the involved degenerative process are attributed to malfunctions of the body's protective immune system. Both humoral and cell mediated responsiveness are thought to play a role in the chronic inflammation (12). The disease may be initiated by some yet unidentified local inflammatory event (antigenic, viral, bacterial or mechanical damage). The two arms of the immune system respond in contrasting ways. Humoral immunity (defence against bacterial and viral invasion) becomes hyperactive leading to tissue destruction due to the production of autoantibodies (antibodies against the bodies' own tissue). Cell mediated immunity CMI, (defence against invading cellular matter, invasive tumor growth) is suppressed, allowing growth of tissue in the inflamed joints. Hyperactive humoral immunity and suppressed CMI are thought to play major roles in the disease processes present in $R A$.

\section{Treatment of RA}

Two groups of drugs are used in the treatment of RA. Nonsteroidal antiinflammatory drugs (NSAIDS) and temission inducing drugs (RIDS) / slow acting antiarthritic dngss (SAARDS). NSAIDS (e.g. aspirin, indomethacin, ibuprofen, naproxen) act symptomatically and serve to relieve pain associated with the disease. In contrast, RIDS in many cases may slow or arrest the progressive joint damage that occurs with $R A$.

The RIDS group comprises several different drug types: antimalarial agents, immunosuppressive agents, and gold compounds. Each of these is associated with side effect potential that limits its clinical usage. Long term use of antimalarial agents has the liability of producing irreversible ocular damage (13). Immunosuppressive drugscarry the risk of inducing the growth of malignant tumours as a result of non-selective suppression of normal immunesurveillance (14). Traditional chrysotherapy, i.e. gold therapy, is associated with numerous side effect potentials, the most severe being exfoliative dermatitis, bone marrow suppression and nephrosis (12).

Gold compoundshave been used with increasing frequency since Forestier's report in 1935. In the United States sodium aurothiomalate (Myochrysine ${ }^{R}$ ) and aurothioglucose (Solganal ${ }^{R}$ ) are the major products. Both compounds must be given by intramuscular injection to be effective. Patients must be monitored frequently for evidence of toxic side effects.

\section{New Developments}

Several years ago SK \& F embarked upon a research programme to develop an improved form of gold therapy. Auranofin (Ridaura ${ }^{R}$ ) is the result of that effort. It is unique in that it is therapeutically effective when administered daily by the oral route.

Auranofin differs chemically from compounds in current use. It is a lipophilic coordination complex of gold(1) stabilised by a phosphine and a thiolate ligand. It exists as a monomolecular species both in the solid state and in solution (15). In contrast, conventional gold compounds have gold(I) coordinated between two thiolate ligands. These compounds are very hydrophilic and polymeric in solution. The lipophilic and monomolecular solution properties of auranofin may facilitate its transport across biological membranes and make it more readily available to modify cellular processes, thus accounting for its oral efficacy.

Although the mechanism of auranofin is not known, it has been shown to exhibit antiinflammatory and antiarthritic properties in experimental laboratory models. It also can affect acute and chronic inflammatory processes as well as cellular and immonopathologic events involved in inflammation and tissue destruction.

In world-wide clinical trials auranofin has been used in treating over 4000 patients with RA. The results indicate that auranofin given orally at a dose of $6 \mathrm{mg}$ per day is comparable in efficacy to parenteral gold compounds in the treatment of RA.

In comparative studies side effects with auranofin were less severe than those with injectable gold causing fewer therapy withdrawals.

\section{Summary}

Autanofin is a new gold compound useful in the treatment of rheumatoid arthritis. It differs from injectable gold by being effective on daily oral administration. This treatment regimen has several advantages. It eliminates pain on injection and the nitritoid reaction associated with injectable gold; it allows for more uniform gold levels and results in a lower incidence of serious side effects requiring withdrawal from therapy.

\section{References}

1 Empire Rheumatic Council Subcommittee, 'Gold therapy in theumatoid arthritis', Ann. Rbeum. Dis., 1960, 19, 95-119

2 Cooperative Clinics Committee of the American Rheumatism Association, 'A controlled trial of gold salt therapy in theumatoid arthritis', Artbritis and Rbeum., 1973, 16, 353-358

3 B.M. Sutton, E. McGusty, D.T. Waltz and M.J. DiMartino, 'Otal gold antiarthritic properties of alkylphosphinegold coordination complexes',J. Med. Chem., 1972, 15, 1095-1098

4 R.C. Blodgett Jr., M.A. Heuer and R.G. Pietrusko, 'Auranofin. A unique oral chrysotherapeutic agent', Semin. Arthritis Rheum., 1984, 13, 255-273

5 G.M. Dyson, 'Gold in chemistry and pharmacy. I The metal and its history', Pharm.J., 1929, 123, 249-250, 266-267

6 J.C. Burnett, 'Gold as a temedy in disease', The Homeopathic Publishing Company, London, 1879 , pp. 28, 127

7 R. Koch, 'Ueberbackteriologische Forschung', Wein. Med. Bl., 1890, 13, 531-535

8 P.D. Hart, 'Chemotherapy of tuberculosis. Research during the past 100 years', Brit. Med. J., 1946, 2, 805, 849

$9 \mathrm{~J}$. Forestier, 'Rheumatoid arthritis and its treatment with gold salts. The results of six years' experience', J. Lab. Clin. Med., 1935, 20, 827-40.

10 J.W. Sigler, G.B. Bluhm, H. Duncan, JT. Sharp, D.C. Ensign and W.R. McCrum, 'Gold salts in the treatment of theumatoid arthritis'; Ann. Intern. Med', 1974, 80, 21-26

11 G.P. Rodnan. C. McEwen and S.L. Wallace, 'Primer on the rheumatic diseases', J. Am. Med. Assoc., 1973, 224, 661-812

12 N.J. Zvaifler, 'Gold and antimalarial therapy', in 'Arthritis and allied conditions', edited by D.J. McCarthy, 9th Ed., Lea and Febiger, Philadelphia, 1979, pp. 364-367

13 See (12) p. 417

14 A.D. Steinberg and J.L. Decker, 'Imunnoregularatory drugs', in 'Arthritis and Allied Conditions', edited by D.J. McCarthy, 9th Ed., Lea and Febiger, Philadelphia, 1979, pp. 375-390

15 B.M. Sutton, 'Overview and current status of gold-containing antiarthritis drugs', in 'Platinum, Gold and Other Metal Chemotherapeutic Agents. ACS Sym. Series 209, Am. Cbem. Soc., edited by S.L. Lippart, Washington D.C. 1983, pp. 355-369 